\title{
Contract Automation: Experiences from Dutch Legal Practice
}

\author{
Author(s) \\ Timmer, Ivar \\ DOI \\ 10.1007\%2F978-981-13-6086-2_6 \\ Publication date \\ 2019 \\ Document Version \\ Author accepted manuscript (AAM) \\ Published in \\ Legal Tech, Smart Contracts and Blockchain
}

Link to publication

\section{Citation for published version (APA):}

Timmer, I. (2019). Contract Automation: Experiences from Dutch Legal Practice. In M. Corrales, M. Fenwick, \& H. Haapio (Eds.), Legal Tech, Smart Contracts and Blockchain (pp. 147-171). (Perspectives in Law, Business and Innovation). Springer. https://doi.org/10.1007\%2F978981-13-6086-2_6

If you believe that digital publication of certain material infringes any of your rights or (privacy) interests,

please let the Library know, stating your reasons. In case of a legitimate complaint, the Library will make the material inaccessible and/or remove it from the website. Please contact the library:

https://www.amsterdamuas.com/library/contact/questions, or send a letter to: University Library (Library of the University of Amsterdam and Amsterdam University of Applied Sciences), Secretariat, Singel 425, 1012 WP Amsterdam, The Netherlands. You will be contacted as soon as possible. 


\title{
CONTRACT AUTOMATION: EXPERIENCES FROM DUTCH LEGAL PRACTICE
}

\author{
IVAR TIMMER
}

\section{Contents}

1 INTRODUCTION

2 METHODOLOGY AND STRUCTURE 2

3 TERMINOLOGY, HISTORY AND DIGITIZATION IN DUTCH LEGAL PRACTICE

3.1 TERMINOLOGY

3.2 HISTORY 6

3.3 DiGITIZATION IN DUTCH LEGAL PRACTICE: A BRIEF OVERVIEW 8

4 EXPERIENCES WITH CONTRACT AUTOMATION $\quad 10$

4.1 REASONS FOR STARTING WITH CONTRACT AUTOMATION 10

4.2 SELECTING THE SOFTWARE $\quad 11$

4.3 SELECTING THE CONTRACTS

4.4 DECOMPOSING AND RECONSTRUCTING CONTRACTS 14

4.5 PERSONNEL IMPLICATIONS

4.6 CHALLENGES AND PITFALLS 16

4.6 FUTURE DEVELOPMENTS 17

4 CONCLUSIONS $\quad 18$

$\begin{array}{ll}\text { REFERENCES } & 20\end{array}$

ABSTRACT Organizations in legal practice, under pressure to do "more for less," are searching for ways to automate legal work, to improve efficiency of legal service delivery. Automated drafting of contracts (or: contract automation) is one of the areas where technology is - partly - replacing legal professionals. In Dutch legal practice, the number of organizations that are actively deploying contract automation is still relatively small, but growing. This chapter looks at experiences with contract automation of organizations from various sectors in Dutch legal practice. Contract automation can improve legal service delivery to consumers and SMEs, as well as contracting processes within organizations. Several organizations report positive results. However, successfully implementing contract automation, especially for internal use within organizations, is not simple. Tight budgets, resistance to change and poor integration with other software are some of the problems that organizations may encounter. Generally, human and organizational factors are often at least as important as the technological aspects. Succesful implementation of contract automation requires design thinking, a proactive approach and process-oriented (legal) professionals.

Regardless of these difficulties, the use of contract automation software in Dutch legal practice can be expected to increase, due to several factors. The number of organizations that are offering contracts (and other legal documents) online to SMEs and consumers has grown rapidly over the last years. Contract automation is not only offered to consumers and SMEs by commercial parties, but also by branch organizations, as a service to their members. Consumers and SMEs will become 
used to these self-help solutions for legal matters. Legal publishers are also increasing the offering of automated contracts and other legal documents. In addition, law firms and consultants are promoting the use of contract automation within client organizations. Finally, many corporate organizations are increasingly exchanging experiences on improving legal operations and the use of Legal Tech, including contract automation. Eventually, increased use of contract automation may drive further harmonization of contracts within sectors and facilitate other technological applications, such as the automated analysis of contracts.

Keywords Contract automation, expert systems, Legal Tech, legal management, legal operations.

\section{Introduction}

Legal professionals perform many tasks that are difficult, or even impossible, to automate. Managing negotiations or conflicts, drafting new contract clauses for new business situations, or exercising wise judgment in situations where legal rules are unclear are but a few examples. However, large parts of the work of legal professionals consist, in essence, of managing and processing information. It is therefore clear that information technology can be useful to support, streamline, or even completely automate legal tasks. Organizations in legal practice, under pressure to do "more for less," are increasingly searching for ways to make use of technology. In his 2008 book The End of Lawyers?, Richard Susskind identified automated document assembly as one of ten disruptive technologies for the legal profession, because of its potential to greatly reduce the time expent by legal professionals on the drafting and production of documents ${ }^{1}$. Over ten years later, this chapter looks into practical experiences of organizations in Dutch legal practice with regard to the automation of a specific type of legal documents: contracts.

In the Netherlands, contract drafting certainly is one of the areas where, in various sectors of legal practice, substantial innovation through information technology is taking place. Several reasons may account for the fact that contract drafting is a favored area for innovation. First, contracts obviously play an important role in many areas of legal practice, from business-toconsumer transactions, government tenders, to, most notably, corporate legal practice. Secondly, contracts often have a repetitive character. For many organizations, it is common to close thousands of similar types of contracts every year, in which each individual contract has only a few variations. In addition, even contracts with a more bespoke character often have many elements in common with other contracts. Finally, from a technical point of view, drafting repetitive contracts is a relatively simple activity. It consists, for a substantial part, of choosing the right text blocks to fit the right situation. This activity can be supported by software that uses questionnaires to connect users' answers, via underlying decision trees and routings, to relevant text blocks. Not too long ago, advanced computer skills were necessary to construct this kind of questionnaires and decision trees and combine it with word processing. Nowadays, this has become much easier and within the reach of non-tech savvy legal professionals, due to the availability of - relatively - user-friendly software. It is self-evident that volume, repetitiveness and the availability of this software are important drivers to increase the pace of digitization and automation.

For this chapter, I have approached organizations from various sectors of Dutch legal practice that are actively involved in automating (parts of) their contract drafting processes. These organizations can be considered frontrunners, even though automation of contract

\footnotetext{
${ }^{1}$ Susskind (2008), p. 101.
} 
drafting can hardly be called a new technology. ${ }^{2}$ However, there are many organizations that have not undertaken any steps in this field, even when their contracting practices appear prima facie ideally suitable for automation. The overall view that emerges is therefore that, although Legal Tech has caught the attention of a broader legal public over the last years, (Dutch) legal practice is in the relatively early stages of digital transformation. Many sectors of legal practice are still conservative when it comes to implementing technology. Another important factor is that many legal departments or organizations only have limited budgets for innovation. Of course, genuine progress has been made with regard to certain aspects. Legal research and information retrieval, for example, have changed unrecognizably in a relatively short period of time, driven by the digitization of legal information by large legal publishers. However, many processes within legal departments or legal service providers are still based on ways of working that originated in a paper age.

Of course, the above does not imply that the automation of contract drafting (and other legal documents) is a must for every organization. The needs of a small legal department that mainly performs bespoke work, will be completely different from those of a large governmental organization or law firm. However, it seems fair to say that in the latter type of organizations one will almost always find documents for which automation may make sense. Ultimately, what makes sense for a particular organization should be decided at an organizational level, by the professionals most involved. Legal professionals therefore have an important role to play when it comes to succesful innovation of legal processes through technology. To quote famous management scientist Peter Drucker on increasing the productivity of knowledge workers:

Continuing innovation has to be part of the work, the task and the responsibility of knowledge workers. ${ }^{3}$

\section{Methodology and Structure}

The basis of this chapter is formed by a series of interviews. ${ }^{4}$ In 2018, a total of 12 professionals and academics, working in the Netherlands, were interviewed, who were all in some way involved in automating contract drafting processes or had studied the automation of legal work from an academic perspective. They were working at a governmental organization, two corporate organizations, ${ }^{5}$ one large and two medium-sized law firms, a legal advisory firm, an online "legal market place," two different software providers, a university and a legal publisher. Their organizations were using software from Thomson Reuters (ContractExpress) and SAP Ariba, as well as software from Dutch providers WeAgree, Berkeley Bridge, Juriblox and LegalThings. Some of these organizations are using the software to offer automated contract drafting online to clients. They sometimes combine this with offering the software as a service to other organizations, e.g., branch organizations, that are then offering contracts to their members or clients under their own label or brand, via a Software As A Service construction (SaaS). Legal departments of corporate organizations are using it in-house to improve legal service delivery to other departments. Others are using it as a part of consulting services, advising or implementing it in other organizations, from governmental organizations to SMEs or large corporate organizations.

\footnotetext{
${ }^{2}$ Susskind points to the article of Sprowl (1979) as the first publication on the subject of document automation in the legal sector

${ }^{3}$ Drucker (1999), p. 84.

${ }^{4}$ Parts of the results, combined with other research, will also be used for the special issue "Law in algorithmic world” of Droit et Société (Université de Liège) for a contribution about the use and implications of rule-based expert systems in Dutch legal practice (expected: december 2019).

${ }^{5}$ A large technological company and a large media production company.
} 
The interviews were held under the condition that results would be anonymized, allowing respondents to speak freely about their experiences. Some of the quotes of respondents have, therefore, been modified slightly, to prevent identification. The results from the interviews were combined with previous experiences and results of earlier research on contract automation, expert systems and Legal Tech in general. ${ }^{6}$ The table below provides an overview of the organizations, the manner in which they use contract automation and the target groups they aim to service with the contract automation. ${ }^{7}$

\begin{tabular}{|c|c|c|}
\hline & Manner of use & $\begin{array}{l}\text { Target group(s) of contract } \\
\text { automation }\end{array}$ \\
\hline $\begin{array}{l}\text { Online legal } \\
\text { marketplace }\end{array}$ & $\begin{array}{l}\text { Offering online contracts } \\
\text { through own website, as well } \\
\text { as via websites of branch } \\
\text { organizations }\end{array}$ & Consumers and SMEs \\
\hline Legal advisory firm & $\begin{array}{l}\text { Offering online contracts } \\
\text { through own website, as well } \\
\text { as via websites of branch } \\
\text { organizations and other } \\
\text { clients }\end{array}$ & Mainly SMEs \\
\hline $\begin{array}{l}\text { Law firms (mid- } \\
\text { size and large) } \\
\text { Law firm (small) }\end{array}$ & $\begin{array}{l}\text { Using contract automation } \\
\text { within the own firm and/or as } \\
\text { part of their consulting } \\
\text { services }\end{array}$ & $\begin{array}{l}\text { Lawyers. In-house legal } \\
\text { departments and/ or other } \\
\text { professionals (e.g., sales } \\
\text { procurement) within these } \\
\text { organizations } \\
\text { Offering contract automation } \\
\text { to SME clients for use in-house }\end{array}$ \\
\hline Legal publisher & $\begin{array}{l}\text { Using contract automation to } \\
\text { improve own products }\end{array}$ & $\begin{array}{l}\text { All clients (mainly legal } \\
\text { departments and law firms) }\end{array}$ \\
\hline $\begin{array}{l}\text { Corporate } \\
\text { organizations }\end{array}$ & $\begin{array}{l}\text { Using contract automation in- } \\
\text { house to improve efficiency } \\
\text { or in-house legal services }\end{array}$ & $\begin{array}{l}\text { In-house counsel and non-legal } \\
\text { professionals within the } \\
\text { organization }\end{array}$ \\
\hline $\begin{array}{l}\text { Governmental } \\
\text { organization }\end{array}$ & $\begin{array}{l}\text { Using contract automation as } \\
\text { as a service to member } \\
\text { organizations }\end{array}$ & $\begin{array}{l}\text { Legal counsel and ICT and } \\
\text { procurement professionals } \\
\text { within member organizations } \\
\end{array}$ \\
\hline
\end{tabular}

The first theme in the interview with the professionals working in legal practice was why and how the organization started with the automation of contract drafting. What were the specific reasons to start, how did the organization select its software and what were the expectations at

\footnotetext{
${ }^{6}$ This research has been conducted as part of the research program on Legal management, at the Amsterdam University of Applied Sciences (AUAS), one of the initiators of the Dutch Legal Tech Alliance, a collaboration between 11 UAS with an LL.B. program, to improve education in Legal Tech. I have also drawn from experiences of students, working in legal practice, in the course Legal service design, part of the master program in Legal management, which is linked to the research program.

${ }^{7}$ The table has been simplified slightly, but displays the most important manners of use and related target groups.
} 
the time? As a second theme, we discussed experiences using and implementing the software, including the integration of the software with other systems within the organization. As a third theme, I asked them whether automating (part of) the contracting process had had any personnel implications, such as a reduction in legal or other professionals, a need for different knowledge and skills of (legal) professionals working within the organization, or an increase or decrease in job satisfaction. Finally, we discussed future developments.

The structure of this chapter is as follows. First, to provide a broader context, some terminology with regards to contract automation will be explained, after which some historic background and an overview of the "state of digitization" of Dutch legal practice will be provided. After this, I will discuss the most important outcomes of the interviews, covering the themes above, split into different subjects and sections. Finally, I will draw some general conclusions, identify challenges and scenario’s and some questions for future research.

\section{Terminology, History and Digitization in Dutch Legal Practice}

\subsection{Terminology}

The automation of contract drafting (contract automation) is, when viewed in the context of the age-old history of law, a relatively new phenomenon. Not surprisingly, the terminology around it has not yet crystallized. In this section, some of the terms used in discussions and literature on contract automation are discussed.

Contract automation can be looked at from a variety of perspectives. First of all, see the introduction, it can be considered a form of automated document assembly (also "document automation," “document assembly” or "automated document generation”). Some regard document automation as part of the broader concept of business process management automation $^{8}$. Viewed from the perspective of legal departments within organizations, contract automation within organizations may indeed often be seen as a specific subset of this discipline. This is the case, because an organization will often really be trying to automate its contracting processes and policies, more than just speed up the drafting process of a specific contract. It will want the right (non-legal) professionals to be able to select, use and compose the right contract, by asking the right questions, preferably without the assistance of or review by the legal department. This whole process goes beyond the mere "legal craftsmanship" of drafting contracts, as contracting policies are directly linked to the (commercial) strategy and risk appetite of an organization. Automating this policy in a large and complex organization requires more than just the intelligent digital composition of text blocks, but demands, amongst other things, effective internal communication, training the professionals involved and continuously monitoring the use of the software. The software on the market often has features to support these process improvements, such as digital workflows and approvals.

Nevertheless, at the core of contract automation lies the use of technology to intelligently combine information to produce (complex) legal documents. It can therefore be viewed as a branch or application of legal informatics. Erdelez and O'Hare describe this field as follows:

The American Library Association defines informatics as "the study of the structure and poperties of information, as well as the application of technology to the organization, storage, retrieval, and dissemination of information.” Legal informatics therefore, pertains to the application of informatics within the context of the legal environment and as such involves law-related organizations (e.g., law offices, courts, and law schools) and users of information. ${ }^{9}$

\footnotetext{
${ }^{8}$ See, e.g., https://www.hotdocs.com/contract-automation

${ }^{9}$ Erdelez and O’Hare (1997), p. 368.
} 
Within the field of legal informatics, systems for contract automation aimed at supporting nonlegal professionals in drafting a contract could be characterized as expert systems: "computer programs which perform complex tasks at a level which is at or near the level expected of a human expert." ${ }^{0}$ Expert systems are traditionally seen as a branch of artificial intelligence, because they mimic a form of human intelligence. A system for contract automation could, more specifically, be characterized as a rule-based legal expert system. Rule-based expert systems are based on rules of logic, such as the modus ponens: if a conditional statement ("if $p$ then q") is accepted, and the antecedent (p) holds, then the consequent (q) may be inferred. ${ }^{11}$ These logical rules are often translated into decision trees. Expert systems have to be programmed by human specialists to deliver specific outcomes for specific scenarios, that have to be conceived beforehand by the programmers. ${ }^{12}$

One could be forgiven for raising an eyebrow over the characterization of an application that produces a relatively simple contract, such as a non-disclosure agreement (NDA), as an expert system and artifical intelligence, because the underlying decision tree or logical rule will have a low degree of complexity. However, there are still plenty of legal departments and law firms that draft relatively simple NDA's on a regular basis and a non-legal professional will certainly lack the expertise to draft a solid NDA from scratch. If a system for contract automation enables a non-legal professional (e.g., a sales or a research \& development professional) to draft a NDA by answering some basic questions, the system performs the role of a human legal expert and could, strictly speaking, qualify as an expert system, albeit for a relatively simple expert task.

With regard to labeling it artificial intelligence (AI); this phenomenon has always been difficult to pin down in a definition. A common joke amongst experts is that things are called AI until the software actually starts working. In the recent past, things such as optical character recognition (transferring scanned typed or written documents into text) were considered AI. Nowadays, most will intuitively associate the term AI with more complex tasks or phenomenons, such as defeating world champions in $\mathrm{Go}^{13}$ or self-driving cars. By way of illustration, natural language processing (NLP) is still an important branch of AI today. Probably, in 25 years or so, young children will consider a person very old, when told that he or she has witnessed the introduction of the first home assistants, such as Amazon's Echo, Apple's Siri and Google's assistant. It seems that defining AI has some resemblances with aiming at a moving target.

Of course, the answer to the question whether or not something is AI or an expert system, is not so interesting in itself. I do consider expert system a fairly useful term, simply because it describes the role a system for contract automation can fulfil within an organization. Some may want to reserve this term for systems that have a high degree of complexity, in which the system has digested a large amount of expert knowledge. They will prefer the term decision support system for systems with a lower degree of complexity. However, one could consider it equally valid for systems that perform relatively simple tasks, as long as the goal is to replace some form of (in-house) expert advice or support. ${ }^{14}$ Within the context of this chapter, this will be the legal expertise needed to craft a professional contract on the basis of facts that the user provides, usually in response to certain questions. Of course, a real contract lawyer may often perform this job better, for example by ascertaining - through additional questioning or other

\footnotetext{
${ }^{10}$ Tyree (1989).

${ }^{11}$ Branting (2017) uses the term logic-based, instead of rule-based, to distinguish from systems using data science tecniques to assist in solving practical legal problems. For example, “robot-lawyer” ROSS, based on IBM's Watson, could be considered a system that is primarily data-centric (or: case-based), although it will, no doubt, use a variety of techniques.

${ }^{12}$ The relatively new phenomenon of Rule-based Machine Learning, in which machine learning is used to identify rules, is usually excluded from the field of "rule-based expert systems."

${ }^{13}$ See https://deepmind.com/blog/alphago-zero-learning-scratch/

${ }^{14}$ Consequently, when a system for contract automation is used by experts themselves to support their own drafting processes, it is not an expert system, but simply a system to facilitate.
} 
forms of research - that the facts provided are indeed correct. To avoid any misunderstanding or controversy, I will simply use the term contract automation software (CAS). I do provide a brief history (and criticism) of legal expert systems and legal informatics in the next section, to promote a critical stance towards the automation of legal work.

Contract automation can be viewed as one of the first steps in the lifecycle of contracts. ${ }^{15}$ Some also include the digital storage and management of contracts under the term contract automation, while others use the term contract management (CM) software for this. In this chapter, I focus on the drafting process and reserve the term contract automation exclusively for the automation of the drafting of contracts. An alternative term for this could be contract assembly, which I do not use, because I have found that some associate this term with assembling contracts using traditional word processing software. Needless to say, there is no right or wrong here, it is simply a matter of definition. A good advice is to start any discussion about the automation of any contracting process with an explanation of the terms used by the participants.

\subsection{History}

Attempts to automate the work of legal professionals go back several decades. Around the 1980s, with the rise of computer science, many universities established research groups in legal informatics and there was an active (inter)national network of researchers in the field of artificial intelligence and law. Several Dutch universities were very active in this field. Legal expert systems were at the center of attention, driven by the enthusiasm over expert systems in other fields. ${ }^{16}$ The research evolved around solving complex legal problems, often for consumer problems (e.g., rent, social security). Reflecting the international situation, expectations of this - relatively - new area were high at Dutch legal faculties. Legal expert systems were generally expected to be able to improve quality, cost-effectiveness and/or accessibility of legal advice or decision-making and the climate for acquiring research funds was favorable. I remember, from my own time at university in the early nineties, debates about whether or not the computer would take over the role of the judge. The opinions were, of course, strongly divided between tecnophiles and conservative lawyers, who dismissed the whole idea as preposterous. To illustrate the attitude towards technology of some legal professionals at the time: when I did an internship at the court of appeals at the time (in 1998), one of the judges refused to use a computer. He simply continued to use his typewriter, which was fully accepted. Today, most legal professionals acknowledge that technology can be a valuable tool, but many are still far from tech savvy. This is probably one of the reasons for the relatively slow pace of technological innovation within legal practice, as well as for the poor quality of many public debates around technology and law today. Debates on Legal Tech often end up discussing the same question as years ago: will technology be able to replace the judge or other legal professionals? This question may be interesting from a philosophical point of view, but we are still lightyears away from any scenario in which full replacement of the complex tasks that legal professionals perform will be possible. A more realistic question is therefore how technology can effectively support legal tasks and processes.

Returning to the developments in legal informatics at the time, constructing and succesfully implementing working legal expert systems, with the aim of - almost - fully replacing legal professionals, proved difficult. As Leith described it:

"The primary reason why the expert systems project failed was that the ambitions were so difficult to achieve. What was being proposed was really the robotisation of lawyers - that their skills and knowledge could be easily formalised, and that as a

\footnotetext{
${ }^{15}$ See e.g. IACCM-CapGemini, 2018

${ }^{16}$ See e.g., Leonard-Barton \& Sviokla, 1988
} 
process was at heart a quite simple operation - if you knew the rules, then you could give advice. This, unfortunately, proved wrong. This was a view which developed from the perceived success of early AI expert system programs, where the argument ran that if they worked in such complex domains as medicine or exploration, they should also work in the 'easier' field of law.” ${ }^{17}$

Leith describes, as another flaw, that these expert systems departed from a over-simplistic view of law, equivalent with the views of Herbert Hart, in his famous book The Concept of Law (1961).

\begin{abstract}
"However, what became clear to me through discussion with my new colleagues was why lawyers of the time were so keen on expert systems in law: they had been brought up in the context of a simplistic rule-oriented view of law of the sort promoted by Hart, and such a perspective neatly dovetailed with the approach used in rule based expert systems. In effect, there was a culture in law of denying the complexity of law. Those who teach in law schools today may be surprised that, 25 years or so ago, most law staff were not socio-legally or contextually inclined. They often taught part-time, did little research, and what research they did do was of the case-notes format. Hart, to this group, seemed perfectly fine in terms of legal philosophy."18
\end{abstract}

And he concludes:

“...any basic critical analysis of a system which is proposed as a 'working legal expert system' will quickly find that the system is not used, over promoted, and generally not much different from a list of boxes to tick.” ${ }^{19}$

In my view, an important part of Leith's criticism comes down to the fact that applying legal rules to complex cases is not a straightforward activity. Even legal rules that appear quite clear will, at a deeper level, always have a certain degree of vagueness or ambiguity, making it hard or impossible to fully capture this in a logical form. Applying a rule means either interpreting the rule, or interpreting the facts that have to be decided. Deciding on legal cases by applying legal rules therefore almost always implies some form of creating law, albeit on a microscale. The use of CAS in legal practice differs both in goals and complexity from the systems that were addressed by Leith's criticism. With regard to the goals: negotiating a contract can be extremely difficult, but the scope of contract automation is much smaller and only focuses on automating the drafting process. With regard to complexity, expert systems often have much higher ambitions than CAS. By way of illustration, researchers at the University of Amsterdam have recently built a modern expert system in the field of labor law. ${ }^{20}$ It consists of over 800 interlinked questions and underlying decision trees. By comparison, most questionnaires for contracts do not exceed 30-40 questions. Nevertheless, Leith's short account does stimulate us to realize the complexity of automating legal work. This important nuance often appears to vanish in today's enthusiasm about the possibilities of Legal Tech.

As another reason for the failure of legal expert systems in the past, Leith points to the fact that the emphasis of the developers was, partly because of the underlying philosophy described above, very much on translating the legal rules into a working system, rather than on the needs of users of the system. Unsuccessful introductions of CAS in organizations can probably often be accredited to insufficient attention to users as well, as we shall see below. Leith's historic account mainly focuses on the British situation, but applies well to the Dutch situation. As a

\footnotetext{
${ }^{17}$ Leith (2010)

${ }^{18}$ Leith (2010)

${ }^{19}$ Leith (2010)

${ }^{20}$ Magontslag.nl
} 
result of, amongst other things, the factors described by Leith, initial enthusiasm and research funding for legal expert systems quickly diminished. Scientific attention for legal informatics remained low for quite some time. On the wave of popular attention for Legal Tech, there appears to be a rejuvenation. However, most scientific attention currently seems directed towards data-centric or "case-based" techniques and the possibility of artificial argumentation and less towards "old-fashioned" rule-based techniques.

Lack of scientific attention aside, organizations in legal practice have certainly continued to develop expert systems and/or systems for decision support, as will be described in the next section.

Goodenough ${ }^{21}$ describes the overall developments in technology for legal practice as a progression from Legal Tech 1.0, to 2.0 and 3.0. In his view, Legal Tech 1.0 is the first phase, which is for a large part based on the digitization of, formerly analog, legal information. This has enabled human professionals to search and work faster, without fundamentally changing legal work. In Goodenough's words: the system has pretty fully digested phase 1.0.

In the second phase (Legal Tech 2.0) technology will actually replace humans. E-discovery practice, where machine learning approaches are replacing large parts of human document review, is a good example of an area where this second phase has arrived. In Goodenough's view, developing expert systems for contract automation is another area where automation may replace human work and legal practice moves beyond "mere digitization." Its potential lies not only within companies, moving legal work from the legal department to other departments, but also at the level of legal services for consumers, where it may empower those who can't (or won't) afford traditional legal advice.

Legal Tech 3.0, according to Goodenough, offers the prospect of more radical innovation, for example by statutes being written in (or at least being well-translatable to) computer code, allowing for the automation of legal processes on a larger scale. Although one could question the extent to which this is possible, it might be feasible for more formalistic areas of law (such as tax law). In many respects, Legal Tech 3.0 is probably still quite far away, but it is clear that more progress lies ahead. For now, as will be described in more detail in the next section, it seems fair to say that Dutch legal practice is in the process of the transformation from Legal Tech 1.0 to 2.0 .

\subsection{Digitization in Dutch Legal Practice: A Brief Overview}

From a perspective of digitization, progress may have been slow, compared to other economic sectors, but the Dutch legal world has certainly changed over the last decades. The Netherlands is a small country, with little over 17 million inhabitants, and Dutch legal practice is consequently relatively small. By way of illustration, there are around 18.000 lawyers (members of the bar), around 12.000 legal professionals working for governmental organizations and around 5.000 legal professionals working for corporate or non-profit organizations. ${ }^{22}$ It is estimated that around 100 Dutch corporate organizations have a legal department of more than ten legal professionals. For most of these corporate organizations, often very internationally oriented, English is the primary legal language. The Netherlands is home to a few large multinationals, such as Philips, ING, Shell, AkzoNobel and Ahold Delhaize. These have more sizeable legal departments (40 to > 500 legal professionals worldwide), but are the exception.

\footnotetext{
${ }^{21}$ https://www.huffingtonpost.com/oliver-r-goodenough/legal-technology-30_b_6603658.html?guccounter=1

${ }^{22}$ These figures represent the legal professionals who are physically working in the Netherlands. In the Dutch legal tradition, legal professionals working for governmental, corporate or non-profit organizations usually are not 'lawyers' in the sense that they are members of the Dutch bar association.
} 
As mentioned in the introduction, across all sectors of Dutch legal practice, legal research and information retrieval have been digitized almost completely; Legal Tech 1.0. As another manifestation of Legal Tech 1.0, virtually all corporate legal departments are working on digitizing their contract management processes, ${ }^{23}$ to complete the transformation from paper to digital contracts. Unfortunately, from a perspective of taxpayer's money and the necessary transformation to complete digital litigation, in 2018 the Dutch judiciary paused an important "Legal Tech 1.0 project," aiming to digitize all forms of litigation. The project, which will continue in a different form and at a slower pace, may serve as a reminder of how difficult it is, in general, to digitize complex legal processes, especially in a conservative sector.

In a broad view, one could characterize the digitization of many other governmental processes as a manifestation of Legal Tech 2.0. In the Netherlands, especially in the domain of social security and environmental law (e.g., building permits), many governmental services of a legal nature have been digitized and automated. Not all of these innovations have been equally successful, but it is fair to say that many have increased both efficiency, speed and userfriendliness of governmental decision-making. The Dutch government is currently also very active in experimenting with Blockchain, to improve legal procedures and processes. ${ }^{24}$

As another sign of continuing digitization and the transformation to Legal Tech 2.0, providers of digital arbitration services have entered the Dutch legal market. The use of ediscovery software (or: software for technological assisted review), another Legal Tech 2.0 development, has increased in recent years. A few governmental organizations, regulators, law enforcement agencies, as well as some of the international tribunals in The Hague, were early adopters in the Netherlands. Law firms have been lagging behind with regard to this particular development, but are making efforts to catch up. In general, virtually all larger law firms and some mid-sized firms are currently investing in technological innovation, with contract drafting as an important area. While some of these firms are genuinely innovative, others still appear to struggle.

With regard to contract automation, as the main subject of this chapter, several alternative service providers have entered the Dutch consumer market. They provide online self-help contracts and other legal documents for consumers and small businesses. They often combine this with functioning as a online market place for law firms and notaries for customers that need more advice. In 2013, a large Dutch retailer entered into a partnership with some notary firms and launched an online notary service ${ }^{25}$ for several standard documents (e.g., a basic will). Other examples are Overeenkomsten.nl, ${ }^{26}$ Omnilegal ${ }^{27}$ and Juriblox. ${ }^{28}$ US provider Rocket lawyer ${ }^{29}$ has also entered the Dutch market. In addition, legal publishers also offer automated legal contract templates to professional users for certain areas of law, such as mergers and acquisitions. ${ }^{30}$

For software that can be used as a "tool box" to automate contracts, on which this chapter focuses, the Netherlands has a few providers: WeAgree, Berkeley Bridge, LegalThings and the aforementioned Juriblox, which also offers their underlying software as a tool box. However, almost all major CAS applications, such as ContractExpress, HotDocs, Exari or NeotaLogic are used somewhere in the Netherlands.

From an international perspective, Dutch legal practice can probably be rated as fairly progressive when it comes to digitization. However, there are differences between and even within sectors, with some organizations lagging behind. To conclude, Legal Tech 1.0 has

\footnotetext{
${ }^{23}$ See Timmer (2016).

${ }^{24}$ www.blockchainpilots.nl

${ }^{25}$ notarisservice.hema.nl

${ }^{26}$ Which in translation means: contracts.nl

27 https://omnilegal.nl/portfolio/omnilegal-doe-het-zelf-oplossing/

${ }^{28}$ https://www.juriblox.nl/

${ }^{29}$ https://www.rocketlawyer.com/nl/nl

${ }^{30}$ https://www.wolterskluwer.nl/producten-diensten/juristen/tools-innovatie/smartdox
} 
mostly arrived, Legal Tech 2.0 is on its way in many parts of legal practice, but Legal Tech 3.0 is still a scenario for the distant future.

\section{Experiences with Contract Automation}

\subsection{Reasons for Starting with Contract Automation}

As mentioned above, the first theme in the interviews with the professionals working in legal practice was why the organization started with contract automation. The respondents identified several benefits, that were often the same for comparable organizations. Many reasons came down to a desire to improve knowledge management by having a "single point of truth" instead of different templates circulating in the organization, increase speed of contract drafting processes, enable non-legal professionals to perform relatively simple legal tasks and to drive down costs and improve efficiency. The following quotes illustrate some of these reasons for the participating organizations.

The governmental organization (the association of Dutch municipalities) had introduced a contract generator (for ICT contracts) as a service to their member organizations.

"We see our 390 members having very similar problems and needs in this field. It makes sense to offer them this tool. We hope it will help them professionalize their ICT contracting practices.”

The corporate organizations both identified as one of their primary goals to transfer simple legal work away from the legal department, to both save time for legal professionals, as well as improve in-house services to other departments.

"This simple work costed us quite some time and, to be honest, it was the least interesting legal work. However, you do want to have some control over it, because the amounts involved can be considerable and the organization could suffer serious risks if legal aspects are not handled properly.”

"Because they don't have to run things by us anymore, it saves the other departments time and actually increases the 'popularity' of Legal."

The online legal market place, acting as a broker between consumers seeking legal advice and law firms, had recently started to use contract automation. It is offering "self-help" consumer contracts on their website, primarily as a marketing tool.

"Developing and maintaining this service may, in itself, not be economically viable, viewed from our specific business model. However, we think clients who use it will be interested in other services of our partners as well.”

The law firms had, amongst themselves, broadly comparable reasons. One identified improving knowledge management as the most important reason.

"Using contract automation software introduces a single point of truth. Before, it was common to have different templates for the same contracts. Now, if we change a clause, it is automatically updated across all contracts.”

Another mentioned speed as an important factor. 
"We wanted to reduce the time to make a first draft. Traditional word processing software has its limitations for that."

Two respondents from law firms stressed the importance of using contract automation as a tool to improve in-house services within their clients’ organizations.

"We help our clients improve their in-house services. With it, we are increasingly moving away from the traditional law firm model."

"I believe that charging for relatively simple and standard documents will be a thing of the past soon. We want to offer a full service package to our SME-clients (small and medium-sized enterprises) with which they can organize their own internal legal affairs. We are no longer charging them to make one contract, but are help them professionalize their legal function."

The argument that increased speed or the possibility of self-help by clients conflicts with the traditional hourly rate model of law firms was discussed with most respondents, from different perspectives. Most agreed that this, in general, had delayed innovation in legal practice and continued to be a factor. However, all agreed that change had set in and that even more conservative law firms were moving towards more innovation and a change in business models. One of the respondents, with a background as a lawyer at a law firm, but now working for a large technological company, had expected in-house legal departments to be further on the innovation curve.

"When I switched from a major Dutch law firm, which I considered to be dinosaurs, to a corporate department a couple of years ago, I expected the corporate world to be a lot more proactive and focused on technological innovation. I must say, I was a bit disappointed, although it is easier to change things here than in a traditional law firm. Fortunately, the general climate is changing and moving towards more innovation.”

\subsection{Selecting the Software}

With regard to the software on the market, a distinction can be made between software that is primarily designed for contract automation (such as ContractExpress, WeAgree or Juriblox), or has broader decision support features (such as Berkely bridge or US Neota Logic), but can also be used for contracts. ${ }^{31}$

Most organizations had not followed an intensive selection procedure before acquiring the software, although most had compared a couple of providers.

"We didn’t really have any experience at the time, so, to be honest, we found it hard to determine what we really needed. We finally relied on a recommendation from someone in our network.”

One law firm had made a deliberate choice for software that allowed for broader applications than just contract automation.

\footnotetext{
${ }^{31}$ Of course, software such as Contract Express and WeAgree can also be used to create other legal documents, such as powers of attorney. However, the software is primarily designed for document automation, as opposed to the software of providers such as Berkeley Bridge and Neota Logic. The latter types could be characterized as "decision tree software," that can be used for various types of decision support, with document automation as an option.
} 
"We like that the software is more generic and allows for more applications than 'plain' contract automation, such as more complex automated decision support whith weighted factors. We use it for other types of processes as well. But for other organizations, simpler may be better. It all depends on your goals.”

That, in most cases, there had been no intensive selection process may have been caused by the fact that all these organizations started early with contract automation. The market for contract automation software is still relatively inmature, but this was certainly the case when the interviewed organizations started, with the first respondent starting over ten years ago. Other research confirms that the market is still developing (IACCM-Cap Gemini 2018). There are various small and indepent providers. Large legal publishers are more actively entering the market, of which the acquisition of Business Integrity (now ContractExpress) by Thomson Reuters in 2015 is an example. Many providers are currently trying to optimize the options of integrating their solutions with related software such as Salesforce. Conversely, providers of applications for enterprise resource management, procurement or contract management, such as SAP Ariba, have also developed modules for contract automation.

"At the time we decided on the software, this was basically a decisions based on relations. Today, we would probably look closer at the possibilities of integration with other software. Contract drafting is just one step in a broader process and the process should be leading in selecting the software."

Almost all respondents acknowledged the integration with other software as a bottleneck, especially within large organizations.

"Sales and procurement use different software, attuned to their needs. Ideally, they would all use the same contract management software with an integrated assembly module, but that's not going to happen. Of course, it is technically possible to integrate the software we use now, but this can be costly and our budget is limited. It is the art of finding the best possible solution in situations that will always be imperfect."

In some interviews the difference between larger and smaller providers were discussed.

"Working with a smaller provider has advantages and disadvantages. Their service and ability to quickly make small changes or fix bugs are usually better - they are simply more agile-, but their budget for truly innovating the software is lower.”

Most respondents indicated that there is a trend towards more attention for organizational and operational aspects of the legal function in organizations, with a strong focus on technology: the "new" field of "legal management" or "legal operations." To illustrate this trend, one could point at the foundation of the Corporate Legal Operations Consortium ${ }^{32}$ in 2016 by some large US corporate departments, with the aim of sharing and developing knowledge and experience on optimizing the legal function. In the Netherlands, several networks facilitate and promote the exchange of experiences, such as the General Counsel Network Netherlands. It appears that legal departments within the corporate sector see themselves as having shared interests towards legal service providers and software providers, rather than seeing each other as competitors. This trend of increased attention for legal operations was strongly reflected within the respondents' organizations.

\footnotetext{
${ }^{32}$ www.cloc.com
} 


\begin{abstract}
"We're looking at all the processes of the legal department, analyzing them and looking for ways to improve efficiency. Technology is almost always in the mix when we redesign it.”

"We're learning from experiences in the field of legal operations, including contract automation, from other organizations in our international network."
\end{abstract}

As as result of this general trend, there are now more options for organizations to be assisted in selecting software and/or inform themselves about their options. Some large consultancy and technology firms have started "legal operations consultancy" or "Legal Tech consultancy."33 In addition, there are websites that compare features of available legal software on the market. ${ }^{34}$

\title{
4.3 Selecting the Contracts
}

As a second theme in the interviews, we discussed experiences using and implementing the software, including good practices, challenges and pitfalls. The following sections cover several of the items, all strongly interrelated, discussed within this second theme.

A first question was which contracts were selected for automation. The answers logically depended on the target groups. The organizations that had implemented CAS for use by consumers or SMEs simply had decided on the basis of their historic data and the contracts that were most used by their clients.

"As we focus on consumers and our historical data tells us which problems our clients encounter most frequently, we have attuned the available contracts to those situations.”

"Of course, there are little differences between sectors, but for SME there is definitely a certain set of contracts that almost all of them will need. We now have around 15 of them programmed. With another round, we will have about 30. More will probably not be necessary. Keeping it manageable is also a factor.”

"We're providing services to business in the ICT sector. Unlike some other sectors of Dutch legal practice, that can be more informal, contracts are important for them. We know quite well what types of contracts they need, simply based on the services we provide them. Our software allows them to draft a professional contract, which we can review for them if desired. This is an option they often select."

Based on the interviews, as well as previous research, arguments may differ within corporate organizations. Sometimes CAS is used first for contracting processes in which speed is of the essence. CAS could then be an alternative for mandated advice or review by legal, especially in routine cases. Other arguments for selection may be a need for multiple users to work together on the same contract, which can be made easier by CAS. However the overall view is that within most corporate organizations using CAS, only a few relatively simple contracts have been automated. The impression is that organizations are planning for more contracts to be automated. Respondents consider collaborating with other stakeholders (e.g., sales, procurement, research and development) of key importance for success.

\footnotetext{
${ }^{33}$ See e.g., https://elevateservices.com/consulting/law-departments/ and https://www2.deloitte.com/global/en/pages/about-deloitte/articles/deloitte-legal-launches-legal-managementconsulting.html

${ }^{34}$ An example from the Netherlands is the (commercial) website www.it-kieswijzer.nl, or the tool developed by the International Association for Commercial and Contract Management and Capgemini, https://software.iaccm.com/. Some of the software providers used by the respondent's organizations can be found in the IT-Kieswijzer, none had yet been examined by the IACCM tool.
} 
Currently, the NDA is probably the overall champion in automation, as a relatively simple contract with high volume in many large corporate organizations.

"We started with the NDA. We also have some straightforward licensing contracts. These are the types of contracts that you don't really want to spend a lot of time on, even though they can be important from financial or other perspectives.”

\begin{abstract}
"Initially, years ago, we programmed all the standard templates that we have, basically as a service to our in-house lawyers. What we saw in practice, was that, over a period of time, they returned to using this only as a repository and were not using the questionnaires. In our current practice, the NDA is the only contract that is available for use outside the legal department. This may sound uneventful, but because we have a lot of them it saves us a lot of time and we consider it a true success. We are currently working to have our contracts for non-strategic procurement available for non-legal professionals, but we are integrating this into the software procurement uses."
\end{abstract}

The last remark holds an interesting observation, that was visible in the practice of other organizations. The use of CAS by legal professionals themselves, as a tool to speed up their own drafting process, appears relatively low and seems most successful when it allows for a lot of data-entry to be skipped, for example by using a link to a Customer Relationship Management (CRM) database, or other databases with relevant information.

\footnotetext{
"Our goal was to have all documents for standard transactions automated, such as the Standard Purchase Agreement and Loan to Market Agreeement. These often involve a whole set of related documents with the same client data. Compiling the set requires a lot of data-entry. Automating them saves time in 'stupid work' and reduces the chance of mistakes."
}

Some of the respondents indicated that they did see potential in increasing the use CAS by legal professionals, for example by optimizing the use of all its features or tying it closer to contracting policies and processes.

\footnotetext{
"We are not really using the clause library now. Possibly, if we would make an effort and update it, it could save us time.”

"If the software would more or less integrate our whole contracting playbook, that could help. Our contract lawyers cannot (and do not have to) memorize our whole contracting policy.”
}

\title{
4.4 Decomposing and Reconstructing Contracts
}

Almost all respondents acknowledged that one of the important benefits of automating legal documents is that it is a unique chance to analyze and redesign contracts.

"It is an excellent opportunity to rethink the whole contract."

However, in doing so, there are quite a few challenges. Some contract templates may have been used for years, without anyone really attempting to change them. The nature of legal work probably stimulates this. When a contract has worked for years, lawyers may fear unforeseen consequences of changing it, even though they might admit that language, wording or design are not perfect. Additionally, legal professionals may consider "their" templates as "their" knowledge and might feel that sharing and redesigning it undermines their position. They may 
also see, in the words of one respondent, certain elements of practice as part of their professional identity and may therefore feel very strongly about certain clauses, customs or phrasings. Several respondents, especially those working with more conservative colleagues, indicated that this aspect was one of the most challenging parts of contract automation.

"To be honest, we didn't go as far as I would have liked. For some contracts, I was happy to have the 'old' version in there, simply to avoid more debate."

"I've seen grown men fight over whether or not definitions should be at the beginning or in an appendix. It's almost unbelievable sometimes...”

Not every respondent experienced these kind of difficulties. Some indicated that working with a relatively young team or in a relatively young business was probably a reason for not encountering much resistance.

"They simply took it as an interesting challenge and were enthusiastic."

Due to limited time, the exact manner in which contracts were redesigned was only briefly discussed in the interviews and could not be analyzed in depth. Nevertheless, an observation was that no respondent made explicit references to the relatively new field of legal information design. This approach departs from a thorough analysis of the needs of users of a contract and stimulates attention for language (for example, by avoiding "legalese") and using other methods and techniques, such as visualizations, to improve comprehensibility and user-friendliness of contracts. This observation concurs with previous findings that most organizations still have a fairly traditional approach to contracts, possibly for similar reasons as described above ("fear of change”), and/or because they are simply unaware of methods and techniques of legal information design. Still, some organizations were certainly making steps in improving their contracts. Several respondents indicated that, when redesigning, their main focus was on shortening the contracts and removing unnecessary clauses. The underlying argument was that a longer and more detailed contract can often trigger debate about relatively unimportant aspects, prolonging negotiations. One respondent emphasized the importance of the use of plain language in stead of legalese.

"I think our strong point is that we dare to use plaiin language to describe things in our documents. Laywers are often afraid to do this, out of a fear of losing nuances."

\subsection{Personnel Implications}

As a fourth theme in the interviews, we discussed personnel aspects, such as implications for staffing and training. A first question concerned the technical skills necessary to be able to program the contracts and the training necessary for using the software. Respondents answered that the software was relatively user-friendly and could be learned to use at a basic to intermediate level in a few training sessions. Most did indicate that overall user-friendliness and "look and feel" of the software could be improved. There appeared to be only small differences between different providers.

Mastering more elaborate skills did not appear to be a problem either, and was done mainly through frequent use and practice, often with the help of the software provider. Maintaining learned skills was a bigger problem, as this requires periodically using the software: "use it, or loose it." Some organizations had only one professional who programmed the contracts, with a few others who had some basic skills. They admitted that this created some organizational vulnerability. 
Most of the respondents thought that programming the contracts should not have to be done by specialized legal professionals, although they deemed it good when these professionals had some basic skills, to understand the possibilities of the software. A paralegal or other support professional could do most of the work in practice.

"I think it's good when our lawyers know how the system works and possibly are capable to make some minor changes. They are responsible for the content, but do not have to be involved in every step. A support professional can manage the software. You need routine. He or she can then also monitor the use of the software, make monthly reports, etcetera.”

Based on the interviews and previous research, most organizations view contract automation as something that can save the legal professionals time, leaving room for more strategic work. Still, it is not uncommon that legal professionals fear the consequences of automation.

"You can sometimes see them think: what is going to happen to my job?"

Of course, fte reduction can be a goal of contract automation. One respondent specifically mentioned a reduction in fte for the legal department as an important goal.

"I do think we have too much lawyers. When all is digitized, I think we can do with less. Maybe a 20\% reduction?”

Apart from a reduction in fte, respondents indicated that contract automation and the overall move towards improving legal operations, required a different type of (legal) professional, in addition to more "classic legal professionals."

"We need more process-oriented legal professionals and more hybrid functions between legal and the business."

"We're now driving the project of contract automation, but I can definitely imagine that we will be positioning it within other departments, such as sales and procurement, with their own professionals doing the work. They will need to have a basis in law, but do not have to be highly specialized legal professionals. There should still be a dotted line between legal and these departments, but it does not have to be our responsibility."

\subsection{Challenges and Pitfalls}

In sections 4.1-4.5, some of the challenges that organizations face have already been discussed. In this section, some other, often related, challenges and pitfalls are discussed, mostly for the situations where CAS is implemented in corporate or governmental organizations. Most are tied to human and organizational factors. Inability to free time for innovation was often identified as a pitfall.

"I do sometimes feel that our organization is like the cavemen in the cartoon, pushing a cart with square wheels, claiming that they're too busy pushing the cart to switch to round wheels. It's hard to break out of the vicious circle.”

"We had one support professional assigned to programming them and it was really hard for him to get the input from the experts. We all have extremely busy agenda's. This slowed things down tremendously.” 
Almost all respondents mentioned or recognized the focus of many legal professionals on substantive issues, rather than on processes, as another factor that complicated innovation.

"Lawyers focus on legal issues, not on processes. They're not used to thinking that way and some don't really like it either. It's like the surgeon only wanting to operate.”

The more general resistance to change by legal professionals, but also by professionals from other departments as well, was another common factor.

"You can duck it, as a contract lawyer. Some like sitting comfortably in their own space, pretending to be busy. Automation and innovation brings this to the surface. That's threatening."

"Lawyers are fond of their own templates and used to their own way of working. If you want them to use it, CAS has to be mandated or the only available option, or some will find a way around it.”

The last remark links to the observation in section 4.3 that the use of CAS by legal professionals themselves appears relatively low. With regard to other decision support systems, previous research has also provided indications that some legal professionals have a tendency to work around these systems. Sometimes this may be because the software is not user-friendly enough. It could also be that users feel that the software does not do justice to their professional skills and feels too much like "ticking boxes," or that they feel checked and monitored. Another reason could be that they want the system to fail, out of fear of change or fear that they might loose their work. I do not have enough information to have a solid opinion and the cases I am referring to were very different. However, I believe that signals such as these, combined with the fact that the list of failed ICT projects is long, are reason enough to never underestimate the importance of a well-structured design and implementation process, that continually involves professionals and other stakeholders. The importance of keeping everyone on board while redesigning contracting processes was a recurring theme in the interviews.

"It's a change process. These are always complex. Never underestimate the psychological aspects."

The organizational structure is a relevant factor that can complicate this change process. Many branches and locations, as well as related differences in organizational cultures, will make implementing CAS more difficult. Finally, tight budgets and economic aspects were frequently mentioned as important complicating factors. Because the legal department is, in non-legal organizations, a support function and a cost center, it can sometimes be hard to present a business case for technological innovation.

\footnotetext{
"Management may see reducing the number of legal professionals as the main opportunity for saving money, while we want to use saved time to improve our services. Framing is important.”
}

\subsection{Future Developments}

Discussing future developments, most respondents answered that they would continue to explore other possibilities of contract automation. The respondents working for the selected law firms saw it as an important part of a new and changed business model. All agreed that contract automation was in the early stages. With several respondents, I discussed possible further changes in the market. Most agreed that contract automation could be a driver for further 
harmonization of contracts in legal practice, with references to other countries being made. For example, documents from the Practical Law Company have a large market share in the UK. Especially for the consumer and SME market, most stated that there are no good reasons for a lot of different templates. They expected that the market would probably see more combinations of software and content ("semi-finished products," that users can attune to their needs) and more integrated solutions.

"A mid-sized company now has to use different types of software. Ideally they would use one solution that covers most or all of their legal needs and can be easily integrated with an ERM software. Things like: content, automation of documents, document lifecycle management, claims, monitoring and reporting. I believe that legal publishers could do more in this area."

The legal publisher, one of the leading publishers in the Dutch market, also identified contract automation as a driver towards more harmonization and an important part of their strategy.

\footnotetext{
"We are transforming from a publisher to a legal service provider. The automation of legal documents, for use by our customers in different contexts, is an important part of this transformation."
}

This respondent also pointed to an interesting side effect. Greater harmonization could eventually make automated analysis of contracts easier. Automated analysis was identified by more respondents as an interesting opportunity for the future, with the first steps already being taken. By way of illustration, Dutch software provider Juriblox recently introduced NDA Lynn: ${ }^{35}$ an AI-application that analyzes NDA's and advises whether or not it is wise to sign it. A technical aspect is that these types of application function better once more data (and data that is more comparable) are available. It is therefore not a surprise that the NDA (high volume, few variations) is currently the first contract for which this type of analysis is introduced. Especially for contracts that have high volume, it is imaginable that AI could automatically analyze contract proposals from a counterparty and advise professionals whether or not this is in line with contract policy, without interference of the legal department. Availability of data is a bottleneck for this, especially for legal documents in the Dutch language. Comparability of data facilitates analysis and could therefore be helped by further harmonization of contracts and contract clauses, driven by legal publishers and/ or branch organizations.

“AI simply needs a lot of data to work well."

\section{Conclusions}

This chapter has provided an overview of some experiences with contract automation within organizations from various sectors of Dutch legal practice. The organizations depicted in this chapter are frontrunners. Most Dutch organizations in legal practice are not yet using any form of contract automation. Nevertheless, the number of organizations that does is growing and the use of contract automation can be expected to increase, due to several factors.

First, the number of organizations that are offering contracts (and other legal documents) online to SMEs and consumers has grown rapidly over the last years. Contract automation is not only offered to consumers and SMEs by commercial parties, but also by branch organizations. It can be expected that consumers and SMEs will increasingly become used to

\footnotetext{
${ }^{35}$ https://www.ndalynn.com/
} 
using contract automation for legal matters. The market for contract automation software is still developing rapidly. Providers of ERM, procurement and contract management solutions are increasingly offering contract automation modules. Legal publishers are also increasing the offering of automated contracts and other legal documents, while progressive law firms and various consultants are promoting the use of contract automation within client organizations. Finally, many corporate organizations are are increasingly exchanging experiences on improving their legal operations and the use of Legal Tech, including contract automation.

Legal service providers (law firms, as well as alternative service providers) that offer contract automation directly to consumers and SMEs basically believe that a business model based on traditional delivery of these type of documents is not sustainable. They trust that the automated contracts and other legal documents they offer for relatively small fees will act as a stepping stone to other, more profitable and complex legal services. These type of providers are slowly disrupting the Dutch legal market. It will become increasingly difficult for legal service providers to have a business model that is based on "manually" delivering relatively standard legal documents.

Within (non-legal) organizations, CAS currently appears to be used most successfully for contracts with high volume, a repetitive character and relatively low complexity, such as NDA's, licensing contracts and contracts for non-strategic procurement. Use for more complex contracts exists, but appears less prevalent. In most cases, CAS enables other departments (e.g., sales, procurement, research and development) to draft their own contracts and reduces or eliminates the need for review by legal.

The use of CAS to speed up the drafting process of contracting professionals, as a sort of advanced word processing software, appears to be low. The reasons for this are unclear and the results may not be representative, considering the low number of respondents. However, a question is whether current CAS on the market is ideally suited for this purpose. Overall, respondents are fairly positive about the user-friendliness of the software when it comes to the way in which contracts can be programmed and the software can be used by non-legal professionals, although they do indicate there is room for improvement. However, it seems fair to assume that the needs of non-legal users using the software to draft contracts are different from the needs of specialized contracting professionals. This is is an interesting theme for future research.

From an organizational point of view, deploying CAS to offer online contracts to external clients is relatively simple. Succesfully implementing CAS within organizations is is more dificult. This can be viewed as a complex change process, in which human and organizational factors are at least as important as technological aspects. Several complicating factors were identified. Legal departments often only have limited time and budgets for (technological) innovation. Legal professionals within organizations regularly demonstrate resistance to change and are primarily oriented towards substantive issues, rather than on processes. Furthermore, integration of contract automation software with other systems within the organization can prove to be complex or costly, especially when client departments (such as sales or procurement) use different software.

Regardless of these difficulties, the research indicates that contract automation - as well as the automation of other legal documents - can bring substantial benefits to organizations. It can move simple legal work away from legal departments, freeing time for more strategic legal work, or simply reducing the number of legal professionals, if desired. Increased speed and the possibility of self-help by other departments may also increase the "popularity" of legal. Another important benefit is that it facilitates monitoring and reporting on the contracting process.

Collaborating with other departments is essential for contract automation to work. Contract drafting is only one step in a process that will involve several departments and should be viewed in an integral manner. For successful implementation, a design thinking approach is necessary: thoroughly analyzing the process, identifying needs of the various users and stakeholders and 
modelling the process accordingly. Of course, in the complex world of organizations, perfection will be hard to attain and compromises will be inevitable. It may, for example, be wise for the legal department to use contract assembly options that procurement or sales software offers, even when these options may not be ideal.

With regard to the automation of the full contract life cycle, many organizations in legal practice are currently still struggling with effectively implementing software for other steps of the process, such as contract management and digital signatures. It seems fair to assume that it will become easier to integrate contract automation (or: Legal Tech 2.0) in organizations, when these Legal Tech 1.0 steps have been taken.

Currently, contract automation still has a fairly low-tech character, with mainly contracts of low complexity being automated. With the continuing digitization of contracting processes, more advanced use of technology may eventually become possible, such as the use of AI for automated analysis of contracts. However - be it Legal Tech 1.0, 2.0 or 3.0 - an important overall conclusion can be that human and organizational factors will always be essential for technology to work.

Acknowledgement: I thank all respondents for their input and inspiring conversations.

\section{References}

Branting (2017) Data-centric and logic-based models for automated legal problem solving. Artificial Intelligence and Law 25(1): 5-27

Leith P (2010) The Rise and the Fall of the Legal Expert System. European Journal of Law and Technology 1(1) http://ejlt.org/article/view/14/1. Accessed 8 Aug 2018

Drucker (1999) Knowledge worker productivity: the biggest challenge. California Management Review 41(2):79-94

Erdelez S, O’Hare S (1997) Legal informatics: application of information technology in law. Annual Review of Information Science and Technology 32:367-402

IACCM-Cap Gemini (2018) Automation Report https://www.iaccm.com/resources/?id=10162. Accessed 20 Aug 2018

Sprowl J-A (1979) Automating the Legal Reasoning Process: A Computer that Uses Regulation and Statutes to Draft Legal Documents. Law and social inquiry, Journal of the American Bar Foundation 4 (1):1-81

Leonard-Barton D, Sviokla J (1988), Putting expert systems to work. Harvard Business Review, https://hbr.org/1988/03/putting-expert-systems-to-work. Accessed 8 Aug 2018

Susskind R (2008) The End of Laywers. Oxford University Press, Oxford

Timmer I (2016) Changing roles of legal: on the impact of innovations on the role of legal professionals and legal departments in contracting practice. Journal of Strategic Contracting and Negotiation 2(1-2):34-47

Tyree A (1989) Expert Systems in Law. Prentice Hall, (New York) 